\title{
The Relationship Between Reading and Intelligence in Primary School Aged Children: Implications for Definitional Models of Dyslexia
}

\author{
Sue M. Cotton ${ }^{1,2}$ and Sheila G. Crewther ${ }^{*}, 1$ \\ ${ }^{1}$ School of Psychological Science, La Trobe University, Victoria, 3086, Australia \\ ${ }^{2}$ Orygen Youth Health Research Centre, Centre for Youth Mental Health, University of Melbourne, Parkville, Victoria, \\ 3052, Australia
}

\begin{abstract}
The validity of definitional models of development dyslexia (DD) derived from the difference between intelligence and reading quotients, is challenged by the failure of these models to consider expected developmental changes in the relationship between these constructs. The purpose of this study was to examine age-related changes in the correlations between verbal and nonverbal intelligence and reading ability. One hundred and twenty six children aged between 7 - 11 years of age were administered the Peabody Picture Vocabulary Test - Third Edition (PPVT-III, a measure of verbal intelligence) the Raven Coloured Progressive Matrices (CPM, as a measure of non-verbal intelligence) and various measures of reading ability (the Neale Analysis of Reading Ability - Revised, NARA, and selected subtests from the Woodcock-Johnson Tests of Achievement- Revised, WJ-Ach). The PPVT-III had significantly stronger correlations than the CPM with reading rate, single word reading, and a measure of text comprehension. Both measures correlated poorly with pseudo-word reading. Despite differences between the two intelligence measures, both correlated more strongly with measures of reading comprehension than with traditionally defined measures of decoding ability. These results are discussed in the context of the validity of current definitions of DD. The need for greater consideration of the appropriateness of certain assessment measures at various ages both in testing and in the interpretation of previous studies, is highlighted.
\end{abstract}

Keywords: Reading ability, verbal intelligence, nonverbal intelligence, dyslexia.

\section{INTRODUCTION}

Developmental dyslexia (DD) is often diagnosed when reading achievement is not commensurate with benchmarks such as intellectual functioning, chronological age, or educational instruction [1]. Definitions of DD based on a discrepancy between intellectual functioning and some measure of reading achievement have been particularly popular, despite wide criticisms regarding usage [2-9]. Such models have been criticized on the basis of poor validity, being more susceptible to effects of regression to the mean, lack of discriminative and predictive power, and unreliability $[3,4,7,10-21]$. Regression-based models have been developed to overcome some of these problems (i.e., regression to the mean). The focus of the majority of these models is centered on the relationship between intelligence and reading achievement and this lingers as a contentious issue.

Toth and Siegel [22] argued that reading and intelligence should be unrelated given the assumption that "dyslexia is caused by some form of highly circumscribed cognitive deficit which does not affect IQ". Others have challenged the empirical validity of this statement arguing that reading disability limits maturation in many other cognitive domains (e.g., vocabulary, general knowledge, etc.) [23-26].

*Address correspondence to this author at the School of Psychological

Science, La Trobe University, Victoria 3086, Australia;

E-mail: s.crewther@latrobe.edu.au
The correlation between intelligence and reading has different roles in discrepancy and regression formulae. For discrepancy-based models, the weaker the correlation between intelligence and reading, then the more reliable the intelligence-achievement difference score [20, 27-30]. Conversely, for regression-based models a stronger relationship between reading and intelligence is required to reduce errors in prediction [27, 31-33]. The challenge is reaching consensus as to what is an acceptable relationship between reading and intelligence, in order to satisfy both theoretical and psychometric specifications.

The correlation between intelligence and reading has been variously estimated to lie between 0.05 to $0.80[20,34-$ 40]. It is likely that the diversity in correlations may be attributed to the measures of intelligence and reading adopted by individual researchers. Measures of reading comprehension tend to be more strongly correlated with intelligence than are measures for orthographic decoding [13, 39, 41]. Measures of verbal intelligence (e.g., verbal intelligence quotient (VIQ), Vocabulary or Peabody Picture Vocabulary Test - Third Edition (PPVT-III)) have also been shown to be more closely associated with reading ability than nonverbal intelligence [13, 19, 40,41]. This is not surprising given that VIQ is derived from tests based on vocabulary, syntactic knowledge, linguistic coding ability, and short-term verbal memory $[13,19,25]$.

The use of VIQ in estimating the relationship between intelligence and reading ability is problematic for two reasons. First, the relationship is likely to be overestimated 
as the same as the language-based abilities underlie performance on both VIQ and reading measures [19]. Second, if a child has compromised language abilities, then VIQ is not necessarily going to reflect the child's true 'intellectual capacity' [7, 12, 15, 19, 36, 38, 40, 42-44]. Poor reading can adversely affect scores on traditional intelligence tests; and conversely, impoverished intellectual capacity can impede reading development [43].

Nonverbal intelligence measures (e.g., matrix reasoning tests) have been considered an alternative to VIQ [14, 36, 37]. Stanovich et al. [40] examined the relationship between the Raven's Standard Progressive Matrices Test (SPM), the Gates-MacGinite Reading Tests, and the Reading Survey of the Metropolitan Achievement Test. Correlations ranged from 0.30 in elementary grades to a high of 0.70 in grades 9 and above. Stanovich et al. [40] did not favour the SPM stating "intelligence tests like the Raven, which do not directly tap a recognized sub-skill of reading, but are instead measures of abstract reasoning or 'mental energy' but supposedly in the quintessence of $g$.... are generally poor predictors of reading ability". Others oppose this view arguing that moderate to large effects exist for the relationship between reading and matrix reasoning tasks [3538].

The child's developmental stage may also influence the strength of the correlation between reading and intelligence [40]. At 5-7 years of age most children have a limited sight word vocabulary and minimal awareness of orthographic and phonologic principles [45]. For very young learner readers, reading is effortful with decoding placing greater demands on attention and other cognitive resources, than text comprehension [25, 40, 45, 46]. With cognitive maturation and the associated learning of orthographic and phonologic principles, reading becomes automatic and fluent, and more attentional resources are available to be allocated to understanding the semantic meaning of the text [46, 47]. This process occurs from 7 years of age and with reading experience and further development of language skills, growth in meta-cognitive abilities (i.e., comprehension and intellectual functioning) can be expected $[43,46]$. Therefore the correlation between reading and intelligence (particularly verbal intelligence) is strongest when the child is a proficient reader, rather than in the early stages of reading development [36-38, 40]. The importance of choice of research measures for different age groups is also highlighted.

In summary, the correlation between reading and intelligence is fundamental to discrepancy and regression based models of DD. If the correlation between reading and intelligence does fluctuate with development as expected, then the psychometric properties of these models must vary depending on the age of the child [20, 27, 31, 48]. These models may also fluctuate depending of the measures of intelligence and reading administered. If such factors are not considered, then the validity of the diagnosis of DD is undermined.

Thus the first aim of the study was to determine verbal intelligence would be a stronger predictor of reading ability than nonverbal intelligence for children aged between 7 and 11 years. Two popular measures of intellectual functioning based on their relative independence of reading ability for successful task completion $[49,50]$ are contrasted; a verbal measure the PPVT-III and a non-verbal measure the Raven's Coloured Progressive Matrices (CPM). We have also elected to use an array of reading measures pertinent to both decoding or comprehension abilities, as the second aim was to establish whether verbal and nonverbal intelligences are more strongly correlated with measures of reading comprehension than decoding ability across all age levels. Here reading comprehension is defined as the ability to analyse, create a mental representation of, and to appreciate what is written in print $[51,52]$. Decoding is defined simply as efficient word recognition or word retrieval [51].

\section{MATERIALS AND METHODOLOGY}

\section{Design}

This is a cross-sectional cohort study of primary school aged children in five age groups: 7 years; 8 years; 9 years; 10 years; and 11 years.

\section{Participants}

The sample comprised 126 children (62 male, 64 females) from two state primary schools within the state of Victoria, Australia ranging in age from 7 to 11 years. These schools were arbitrarily selected from two of the nine Department of Education, Employment and Training (DEET) regions to ensure sample diversity. The two regions were the Northern and Southern Metropolitan regions. Active parental consent [53] was sought for each child as prescribed by the State Government and institutional ethics committees. Children were issued a consent form, which parents completed and returned the form if they wished their child to participate in the study.

A priori sample size calculations and power analysis were conducted using the software package Sample Power Release 2 [54]. Given previous reports of moderate to strong correlations (i.e., $r=0.30$ to $r=0.50$ ), an alpha of .05 , and power set at .80 ; between 26 and 82 children were required for the study. Sufficient power to detect both moderate to large effects was assumed with the obtained sample of 126 children.

Children were excluded from the study if they had a diagnosis of mental retardation (e.g., intelligent quotient (IQ) $<70$ ), neurological anomalies (e.g., epilepsy, traumatic brain injury), did not speak English as a first language, or they had visual or hearing impairments that may have impeded reading acquisition.

Data were collected between February 2002 and November 2004.

\section{Measures}

The measures selected for use in this study have frequently been employed in the learning and reading disability literatures for diagnostic purposes.

\section{Intellectual Ability}

Two different measures of verbal and nonverbal intellectual functioning where selected: the PPVT-III and the CPM. Dunn \& Dunn (1997) advocated that the PPVT-III serves two purposes: first, to measure an individual's listening comprehension or receptive vocabulary; and second, to serve as a screening tool for verbal ability [49]. A 
Task Force under the guidance of the Board of Scientific Affairs (BSA) of the American Psychological Association (APA) highlights the PPVT-III as a discrete measure of verbal intelligence [55] assessing the ability to select from an array of four pictures, the picture that best represents the spoken word. It has demonstrated usefulness in populations such as gifted children, children with mental retardation, autism, cerebral palsy, expressive language deficits and DD [49]. Its value for assessing receptive vocabulary or estimating verbal intelligence in DD is of particular importance, as it does not require reading or writing for successful test performance. On this basis, it has been argued that it represents the purest measure of verbal ability in these children [49].

The $C P M$ is a nonverbal matrix reasoning task that estimates the nonverbal component of Spearman's $g$ factor [50]. It provides an unbiased estimate of fluid intelligence for children with reading or language disabilities $[35,40]$. It comprises 36 brightly coloured items differing in terms of increasing complexity. A multiple choice response style is demanded with children selecting the best fitting piece from an array of six stimuli.

The PPVT-III and the CPM are both reliable measures $[49,50,64]$. Additionally, both measures have been validated against other intelligence measures. For example, the PPVT-III correlates strongly with traditional indices of intelligence such as FIQ $(r=.90)$, VIQ $(r=.91)$, and PIQ $(r$ $=$.90) [49]. Similar correlations have also been noted in other studies [56, 57]. The CPM also has strong correlations with FIQ $(r=.91)$, VIQ $(r=.84)$, and PIQ $(r=.83)$ from the WISC [58]. It is important to note that the PPVT-III and CPM are not perfectly correlated with the Wechsler Scales, with some variance being left unexplained.

\section{Reading Ability}

Neale Analysis of Reading Ability - Revised (NARA) [59] comprises graded short-passages and through assessing a child's oral reading skills derives indices of conventional reading speed, accuracy, and comprehension. Reading Rate provides an index of the child's normal reading speed and is converted to the number of words read per minute. Reading Accuracy is the number of errors accumulated when reading the passages and reading Comprehension involves assessment of what the child remembers regarding the content of the passages. The NARA has been standardized Australian primary school children and for children in several other countries, making it an ideal reading measure for the present study.

Reading-related subtests from the Woodcock-Johnson Tests of Achievement (WJ-Ach) were used [60]. Letter-Word Identification gauges both the ability to identify and recognize a series of isolated letters and words, and can be considered a measure of both sight word recognition and decoding ability [61]. Word Attack is a pseudo-word reading task that evaluates phonic and structural analysis skills. Pseudo-word reading is the purest index of decoding ability devoid of lexical content [62, 63]. Passage Comprehension is a cloze sentence task requiring the silent reading of a sentence and naming of a missing word. Reading Vocabulary assesses both word recognition and the ability to name words with similar (synonyms) or opposite (antonyms) meanings [60].

\section{Procedure}

All tests were administered to the children by trained clinicians. Standard administration guidelines were followed. Children were individually assessed in a quite room separate from their main classrooms. Two one hour sessions were conducted on separate days approximately one week apart. Test order was counterbalanced to minimize the effects of test order bias.

\section{Data Analysis}

Analyses were based on standard scores with a mean of 100 and a standard deviation of 15 . Standard scores were unavailable for the NARA and the CPM and had to be calculated. Standard scores for the NARA were derived using the raw scores for Rate, Accuracy, and Comprehension compared to the age-appropriate averages and standard deviations reported by Neale (1991). The CPM standard scores were calculated using descriptive data from a normative study for primary school children from Victoria Australia [56].

Some children had incomplete data; however, the percentage of missing data per variable was no more than $5 \%$ (i.e. 6 cases). Using, Little's MCAR test from the Missing Value Analysis module of the Statistical Package for the Social Sciences 15.0 (SPSS), it was determined that there was no significant discrepancy between the pattern of missingness and 'missing completely at random' (MCAR), $\chi^{2}(91)=94.487, p=.380$, and accordingly missing data was imputed using the expectation maximization (EM) algorithm [65]. This method of imputation is superior to mean substitution and regression methods as it does not overestimate the variance or interfere with covariance matrices [65]. The complete data set created through the EM algorithm was used in the proceeding analyses.

Several techniques screened the data for normality, heteroscadisticity, homogeneity of variance, and for outliers, including visual inspection of histograms, boxplots and scatterplots, as well as checking of statistics such as skewness, kurtosis, and the Kolmogorov-Smirnov test. No outliers were observed and there were no violations to the statistical assumptions.

A diverse range of statistical techniques were used for data analysis, including Pearson Product Moment Correlation Coefficients (Pearson's $r$ ), the William's $t$ test, factor analysis, and standard regression analyses.

Pearson Product Moment Correlation Coefficients (Pearson's $r$ ) were employed to examine the zero-order relationships between the reading measures, the PPVT-III, and the CPM. The criteria used to evaluate the strength of Pearson's $r$ were $r=.1$ a small effect, $r=.3$ a moderate effect, and $r=.5$ a large effect [66]. These correlations are reported for both the total sample of 126 children as well as separately for the five age groups.

To establish whether the PPVT-III had significantly higher correlations than the CPM, with the reading measures, the William's $t$ test was adopted. This statistic tests the hypothesis that there will be no statistical difference between 
two correlations from dependent samples $\left(\mathrm{H}_{0}: \rho_{Z X}=\rho_{Z Y}\right)$ [67]. For example, the William's $t$ test can be used to determine whether a correlation of 0.69 is significantly higher than a correlation of 0.45 . The formula for William's $t$ test is as follows:

$$
t=\frac{\left(r_{Z X}-r_{Z Y}\right) \sqrt{(N-3)\left(1+r_{X Y}\right)}}{\sqrt{2|R|+\frac{\left(r_{Z X}-r_{Z Y}\right)^{2}\left(1-r_{X Y}\right)^{3}}{4(N-1)}}}
$$

where $|R|$ is the determinant of the correlation matrix $\mathrm{R}$.

This statistic is distributed on a $t$ distribution and can be compared to a critical value of $t$ with degrees of freedom (df) $N$ - 3. In this study, as the hypothesis was directional a onetailed test was used with an alpha $(\alpha)$ of .05. That is, does the PPVT-III have a significantly higher correlation with a reading measure than the CPM? Additionally, these analyses were confined to the total sample rather than to the separate age levels because of limited sample size.

As there were several reading measures, principal axis factor analysis with direct oblimin (oblique) rotation was to reduce the number of variables. Factor scores were derived using the regression approach. They have a mean of 0 and a variance that equates to the squared multiple correlation (SMC) between the variables and the factors [65]. These factor scores were transformed so they were on the same scale as the other measures (i.e. a mean of 100 and a standard deviation of 15). The correlations of the PPVT-III and the CPM with these factors were then contrasted using the William's $t$ test.

A series of multiple regression analyses examined the combined contribution of the CPM and the PPVT-III to the explanation of variance in each of the reading measures.

\section{RESULTS}

Descriptive statistics (means and standard deviations) for the intelligence and reading measures for the total sample as well as for the five age levels is displayed in Table 1. A series of one-way analysis of variance (ANOVAs) determined the comparability of the age groups on each of the measures. There were no significant differences between any of the age groups on any of the measures and all means were within the 'average' range (standard score range 90109 [68])

Table 2 comprises the Pearson correlations of the PPVTIII and the CPM with the various measures of reading ability for the total sample as well as for the five age groups. Correlations for the overall sample ranged from weak to moderate, with the PPVT-III having stronger correlations with the reading measures than the CPM. Significant differences, as determined by the results of the William's $t$ tests, between the correlations of the CPM and the PPVT-III were noted for: Rate, William's $t(123)=-1.88, p=.031$; NARA Comprehension, William's $t(123)=-1.92, p=.029$; Letter-Word Identification, William's $t(123)=-1.78, p=$ .039; and Reading Vocabulary, William's $t(123)=-2.13, p=$ .0 .18 .

Noteworthy is that the strength of the correlations between the CPM and the PPVT-III with the reading measures appeared to fluctuate with the age of the child. For the 7-year olds, there were no relationships between the intelligence and reading measures, whereas for the 8 year olds there was a sudden increase in the strength of the associations, to the point where significant moderate to strong correlations were observed. The strength of the correlations declined slightly with age, particularly those correlations between the CPM and reading. At 11 years of age, the correlations between the intelligence and reading measures once again strengthen.

The pattern matrix from the principal axis factor analysis based on the total sample is displayed in Table 3. Two factors were derived from the factor analysis. The first factor represents 'Decoding' ability with variables loading highest on this factor including Word Attack, Accuracy, Letter Word Identification and Rate. The second factor was representative of 'Comprehension' of written material with variables loading highest on this factor including Reading Comprehension, Passage Comprehension, and Reading Vocabulary. 'Decoding' accounted for $69.43 \%$ of the variability, and 'Comprehension' explained $5.05 \%$ of the variance.

Table 1. Descriptive Statistics (Means $=M$ and Standard Deviations $=$ SD) for Intelligence and Reading Measures for Each Age Level and for the Total Sample $(n=126)$

\begin{tabular}{|c|c|c|c|c|c|c|c|c|c|c|c|c|}
\hline \multirow[b]{2}{*}{ Measure } & \multicolumn{2}{|c|}{$\begin{array}{c}\text { Total Sample } \\
(\mathrm{n}=126)\end{array}$} & \multicolumn{2}{|c|}{$\begin{array}{l}7 \text { Years } \\
(n=19)\end{array}$} & \multicolumn{2}{|c|}{$\begin{array}{l}8 \text { Years } \\
(n=27)\end{array}$} & \multicolumn{2}{|c|}{$\begin{array}{l}9 \text { Years } \\
(n=23)\end{array}$} & \multicolumn{2}{|c|}{$\begin{array}{l}10 \text { Years } \\
(n=32)\end{array}$} & \multicolumn{2}{|c|}{$\begin{array}{c}11 \text { Years } \\
(n=25)\end{array}$} \\
\hline & $M$ & $S D$ & $M$ & $S D$ & $M$ & $S D$ & $M$ & $S D$ & $M$ & $S D$ & $M$ & $S D$ \\
\hline CPM & 99.01 & \pm 13.32 & 100.65 & 16.09 & 96.81 & 14.06 & 101.53 & 9.82 & 98.13 & 15.06 & 98.95 & 10.92 \\
\hline PPVT-III & 96.71 & 13.12 & 100.21 & 13.69 & 95.07 & 12.61 & 97.75 & 13.48 & 98.94 & 12.8 & 92.00 & 12.74 \\
\hline NARA Rate & 101.84 & 14.04 & 101.21 & 14.84 & 104.04 & 14.96 & 100.96 & 17.05 & 101.51 & 10.94 & 101.17 & 13.85 \\
\hline NARA Comprehension & 96.78 & 12.06 & 104.02 & 13.75 & 97.41 & 11.86 & 94.74 & 10.99 & 95.14 & 11.82 & 94.57 & 10.82 \\
\hline Letter-Word Identification & 104.11 & 18.79 & 108.14 & 17 & 107.52 & 23.09 & 101.35 & 15.97 & 104.16 & 16.67 & 99.84 & 20.01 \\
\hline Passage Comprehension & 97.75 & 12.47 & 103.87 & 10.57 & 99.85 & 16.68 & 96.92 & 9.59 & 97.31 & 10.56 & 90.64 & 12.68 \\
\hline Word Attack & 106.77 & 21.78 & 106.88 & 21.96 & 111.18 & 24.19 & 103.98 & 23.65 & 105.91 & 17.87 & 105.6 & 22.75 \\
\hline
\end{tabular}


Table 2. Pearson Zero-Order Correlations Between Measures Verbal and Nonverbal Intelligence and Reading Ability for the Total Sample of 126 Children and for the Five Age-Levels

\begin{tabular}{|c|c|c|c|c|c|c|c|c|c|c|c|c|}
\hline & \multicolumn{2}{|c|}{$\begin{array}{c}\text { Total } \\
\text { Sample }\end{array}$} & \multicolumn{2}{|c|}{$\begin{array}{l}7 \text { Years } \\
(n=19)\end{array}$} & \multicolumn{2}{|c|}{$\begin{array}{l}8 \text { Years } \\
(n=27)\end{array}$} & \multicolumn{2}{|c|}{$\begin{array}{l}9 \text { Years } \\
(n=23)\end{array}$} & \multicolumn{2}{|c|}{$\begin{array}{l}10 \text { Years } \\
(n=32)\end{array}$} & \multicolumn{2}{|c|}{$\begin{array}{l}11 \text { Years } \\
(\mathrm{n}=25)\end{array}$} \\
\hline & CPM & PPVT-III & CPM & PPVT-III & CPM & PPVT-III & CPM & PPVT-III & CPM & PPVT-III & CPM & PPVT-III \\
\hline NARA Rate & 0.15 & $0.33 * *$ & 0.01 & -0.06 & $0.41^{*}$ & $0.41 *$ & 0.09 & $0.49^{*}$ & 0.03 & 0.23 & 0.26 & $0.55^{*}$ \\
\hline NARA Accuracy & $0.28 * *$ & $0.41 * *$ & 0.06 & 0.04 & $0.68 * *$ & $0.59 * *$ & 0.35 & $0.65 * *$ & 0.01 & $0.41^{*}$ & 0.34 & $0.48 *$ \\
\hline NARA Comprehension & $0.37 * *$ & $0.53 * *$ & 0.17 & 0.22 & $0.78 * *$ & $0.54 * *$ & 0.39 & $0.75^{* *}$ & 0.17 & $0.37 *$ & $0.51 * *$ & $0.86^{* *}$ \\
\hline Letter-Word Identification & $0.25 * *$ & $0.41 * *$ & -0.06 & -0.03 & $0.70 * *$ & $0.59 * *$ & 0.29 & $0.43^{*}$ & -0.01 & $0.36^{*}$ & 0.25 & $0.52 * *$ \\
\hline Passage Comprehension & $0.38 * *$ & $0.51 * *$ & 0.02 & 0.20 & $0.65 * *$ & $0.67 * *$ & $0.42 *$ & $0.65 * *$ & 0.31 & 0.32 & $0.49 *$ & $0.55 * *$ \\
\hline Word Attack & $0.20 *$ & $0.26^{* *}$ & -0.08 & -0.24 & $0.69 * *$ & $0.54 * *$ & 0.27 & 0.33 & -0.04 & 0.17 & 0.16 & 0.39 \\
\hline Reading Vocabulary & $0.42 * *$ & $0.59 * *$ & 0.25 & 0.24 & $0.69 * *$ & $0.72 * *$ & 0.37 & $0.49^{*}$ & 0.28 & $0.49 *$ & $0.53 * *$ & $0.77 * *$ \\
\hline
\end{tabular}

$* \mathrm{p}<0.5 ; * * \mathrm{p}<.01$.

The William's $t$ test was used to contrast the correlations that the PPVT-III and the CPM had with the two factors. There was no difference between the PPVT-III ( $r=0.39$, $p<.01)$ and the CPM $(r=0.26, p<.01)$ with respect to their correlations with the 'Decoding' factor, William's $t(123)=$ $1.41, p=.08$; however, the PPVT-III $(r=0.59, p<.01)$ had a significantly higher correlation with the 'Comprehension' factor, than did the CPM $(r=0.39, p<.01)$, William's $t(123)$ $=-2.30, p=.011$.

Table 3. Factor Loadings from a Principal Axis Factor Analysis with Direct Oblimin Rotation Depicting the Underlying Relationships Between Different Measures of Reading Ability

\begin{tabular}{|l|c|c|}
\hline \multicolumn{1}{|c|}{$\begin{array}{c}\text { Reading } \\
\text { Measure }\end{array}$} & $\begin{array}{c}\text { Factor 1 } \\
\text { Decoding }\end{array}$ & $\begin{array}{c}\text { Factor 2 } \\
\text { Comprehension, }\end{array}$ \\
\hline \hline Word Attack & $\mathbf{1 . 0 5}$ & -0.15 \\
\hline NARA Accuracy & $\mathbf{0 . 7 7}$ & 0.18 \\
\hline Letter-Word Identification & $\mathbf{0 . 7 2}$ & 0.25 \\
\hline NARA Rate & $\mathbf{0 . 5 2}$ & 0.20 \\
\hline NARA Comprehension & -0.05 & $\mathbf{0 . 7 5}$ \\
\hline Reading Vocabulary & 0.15 & $\mathbf{0 . 7 5}$ \\
\hline Passage Comprehension & -0.04 & $\mathbf{0 . 9 0}$ \\
\hline Percent of variance explained by factor & $69.43 \%$ & $5.05 \%$ \\
\hline
\end{tabular}

The PPVT-III had significantly higher correlation with 'Comprehension' than with 'Decoding', William's $t=-5.81$ $p<.01$. A similar result was obtained for the CPM as it had a significantly higher correlation with 'Comprehension' than it did with 'Decoding', William's $t=-3.50, p<.01$.

Table 4 comprises the Multiple $\mathrm{R}^{2}$, standardised regression $(\beta)$, and semi-partial squared $\left(s r^{2}\right)$ coefficients for each regression analysis. For the 'Comprehension' factor, nearly $40 \%$ of the variance was explained by both the PPVTIII and the CPM, compared with only $17 \%$ of the variance in the 'Decoding' factor. The PPVT-III and the CPM explained the least amount of variability (only 8\%) in pseudo-word reading.
In summary, the PPVT-III as a measure of verbal intelligence was significantly more strongly correlated than the CPM with the rate of reading, single-word reading, vocabulary or word knowledge, and understanding of what was read in a text. Overall, both verbal and nonverbal intellectual ability was more strongly correlated with text comprehension rather than with measures of orthographic and phonological decoding.

\section{DISCUSSION}

Understanding and quantifying the relationship between intelligence and reading ability is fundamental for the validity and reliability of the discrepancy- and regressionbased models of DD. This study explored the relationships of two measures of intellectual ability, namely the PPVT-III and the CPM, with an array of reading tests. Correlations between reading and intelligence measures ranged from 0.15 (for Rate and CPM) to 0.53 (for NARA Comprehension and the PPVT-III) (refer to Table 2), indicating that for this sample of children, intelligence explains approximately $29 \%{ }^{1}$ of the variability in reading ability which is lower than previous estimates [35-40]. A reason for this disparity is that earlier studies have administered group based tests to large samples of children [35, 37, 38, 40]. Group administered tests differ from individually administered tests in terms of form, design of questions, response format, flexibility, and norms [32].

\section{Intelligence, Decoding and Reading Comprehension}

Reading ability can be subdivided into a number of subcomponents $[46,51,69,70]$ and in this study factor analysis revealed two factors: 'Decoding' (explaining $69.43 \%$ of the variability) and 'Comprehension' (explaining $5.05 \%$ of the variability). Measures loading on the 'Decoding' factor included reading speed and accuracy, word identification, and pseudo-word reading, with this factor explaining nearly $70 \%$ of the variability in reading ability. Neither the PPVT-III nor the CPM had strong correlations with the 'Decoding' factor, and these two intelligence measures combined to account for only $17 \%$ of

\footnotetext{
' Coefficient of determination $\left(r^{2}\right)$ for the correlation between NARA Comprehension and the PPVT-III.
} 
Table 4. Multiple $\mathbf{R}^{2}$, Standardized Regression Coefficients $(\beta)$ and Squared Semi-Partial Correlations (sr $\left.{ }^{2}\right)$ from a Series of Standard Regression Analyses with the PPVT-III and the CPM as Predictors of Reading Ability

\begin{tabular}{|c|c|c|c|c|c|}
\hline \multirow{2}{*}{ Measure } & \multirow{2}{*}{$R^{2 \mathrm{a}}$} & \multicolumn{2}{|c|}{ CPM } & \multicolumn{2}{|c|}{ PPVT-III } \\
\hline & & $\boldsymbol{\beta}^{b}$ & $s r^{2 c}$ & $\beta$ & $s r^{2}$ \\
\hline 'Decoding' factor & $.168 * *$ & .136 & .016 & $.341 * *$ & .101 \\
\hline NARA Rate & $.110^{* *}$ & .035 & .001 & $.318^{* *}$ & .088 \\
\hline NARA Accuracy & $.184 * *$ & .137 & .016 & $.360 * *$ & .112 \\
\hline Letter-Word Identification & $.180 * *$ & .113 & .011 & $.371^{* *}$ & .119 \\
\hline Word Attack & $.079 * *$ & .112 & .013 & $.213^{*}$ & .039 \\
\hline 'Comprehension' factor & $.388 * *$ & $.221 * *$ & .042 & $.508 * *$ & .225 \\
\hline NARA Comprehension & $.322 * *$ & $.207^{*}$ & .037 & $.459 * *$ & .183 \\
\hline Passage Comprehension & $.301 * *$ & $.221 * *$ & .042 & $.428 * *$ & .159 \\
\hline Reading Vocabulary & $.394 * *$ & $.238 * *$ & .049 & $.502 * *$ & .219 \\
\hline
\end{tabular}

the variability in this factor. The lack of disparity between the PPVT-III and CPM is interesting given claims that measures of nonverbal intelligence are unimportant for learning to read $[34,71,72]$.

Although the PPVT-III and the CPM correlations with 'Decoding' factor did not differ, differences were found with individual measures loading on this factor. The PPVT-III had significantly stronger correlations with reading rate and single word reading than the CPM; however, no differences were found for pseudo-word reading and reading accuracy. Models of word reading may aid in the interpretation of these findings. It has been hypothesized that two distinct but interrelated processes underpin the ability to recognize single words; the first is phonological decoding of words, and the second is orthographic analysis of the word's structure [51, $73,74]$. Both processes are necessary but neither are sufficient for skilled word reading [73]. It may be the case that Rate from the NARA and Letter-Word Identification are more indicative of orthographic skills than phonological ability. The reverse may be true for Word Attack, a reported pure measure of phonological decoding ability [74]. Accuracy from the NARA may represent an exception to this distinction as higher scores on this task may depend on phonological and orthographic decoding, as well as articulation. It appears that the PPVT-III has stronger correlations with tasks more dependent on orthographic decoding than those requiring phonological analysis of words. A child with an enriched vocabulary is more likely to rapidly recognize words and read at a faster rate, than a child with an impoverished vocabulary who neither has access to a familiar word nor has a template of semantic expectancy of the word [40, 43, 51]. Conversely, simple pseudo-word reading, a measure devoid of both lexical and semantic factors, is less likely to be constrained by either verbal or nonverbal intelligence [63]. Such generalisations, however, are limited by the lack of a clear differentiation and understanding of what cognitive abilities underpin these measures of 'Decoding'.
The divergence between correlations of the PPVT-III and the CPM with 'Comprehension' is not unforeseen. Measures of verbal intelligence share the same underlying cognitive abilities as reading comprehension: vocabulary, short-term memory, linguistic understanding, and acquired knowledge. As the PPVT-III assesses both listening comprehension and receptive vocabulary, a greater shared variance with the 'Comprehension' would be predicted. It should also be highlighted that both measures of intellectual ability combine to explain approximately $39 \%$ of the variability in 'Comprehension', which is over double that explained in 'Decoding', highlighting that decoding and comprehension are largely independent in terms of information processing [52].

Comprehension from the NARA and Passage Comprehension from the WJ-R Ach differed in their relationships with the PPVT-III and the CPM. For Passage Comprehension there was no significant difference between its correlations with the PPVT-III and the CPM, whereas the NARA Comprehension had a significantly higher correlation with the PPVT-III than the CPM, highlighting that although the two measures are purported to assess reading comprehension they are measuring distinct aspects of reading and require different underlying skills for successful performance on each task [63]. Nation and Snowling reported that word recognition was more important for comprehension tasks involving sentence completion whereas for text comprehension tasks such as the NARA, listening comprehension was a better predictor of ability. That is, unsurprisingly higher level linguistic ability, related to verbal intelligence, is more crucial for text comprehension tasks.

\section{Age and the Relationship Between Intelligence and Reading}

The research observations described here mainly pertain to the total sample of children of 126 children aged between 7.00 and 11.92 years. Noteworthy, however, is that the 
correlations between reading and intelligence measures seemed to fluctuate with the age of the child. For the 7 year olds, there was no relationship between the measures of reading and intellectual abilities; conversely for 8 year olds, the strength of the correlations increased dramatically, particularly the correlations of the CPM with the Accuracy, NARA Comprehension, Word Attack, Letter-Word Identification. However, the CPM, became less important beyond 8 years, with the PPVT-III being more strongly related to these reading variables. Age-related changes in the association between reading and intelligence have been previously reported with the correlations generally augmenting in strength with age $[19,36,39,40,75]$. However, further examination of the developmental changes in the association are important given that the correlations obtained in the current study indicate that distinct aspects of intelligence and reading may be pertinent at different ages. However, the small sample sizes within each age group, limits our ability to infer the extent to which this may be the case.

\section{Implications}

There are several implications of these findings for the diagnosis of DD. First, fluctuations in the strength of the association can impact directly on the reliability of discrepancy and regression formulae. A strong correlation between scores on intelligence and reading measures (e.g. between Comprehension and PPVT-III) is desirable for regression formulae, reducing the chances of making errors in prediction $[32,33]$. Alternatively, such a strong correlation would be likely to reduce the reliability and increase the standard error of measurement for the discrepancy score [27]. Hence, the likelihood of accurate diagnosis will depend on which measurement tools are administered and the statistical model adopted.

A second related concern is the relationship of measures of intelligence with pseudo-word reading. Current views of DD are that it is a manifestation of deficits in phonological processing or the ability to process sound-to-grapheme correspondences $[1,62,63,72,77]$. Pseudo-word reading tasks are often purported to provide the best method of measuring phonological decoding ability [13, 62, 63]. Both verbal and nonverbal intelligence, however, have little impact on pseudo-word reading [13], and in this study the PPVT-III and the CPM only accounted for $8 \%$ of the variability in scores on Word Attack. If such tasks are implemented in discrepancy or regression formulas, the resulting diagnosis is likely to be invalid with high rates of both false positive and false negative diagnoses. With high rates of false positive clinical research groups are likely to be heterogeneous. This heterogeneity is likely to reduce generalisability of results and may account for inconsistent findings across studies. For example, it has been claimed that if measures such as VIQ or PPVT are used in the diagnosis of $\mathrm{DD}$, then a deficit in pseudo-word reading is clearly apparent in children with reading problems [74]. This 'deficit' has been observed to dissipate when PIQ or the matrix reasoning tasks are used to identify children with reading problems [74]. Such studies do not consider the poor association between both verbal- and non-verbal intelligence and pseudo-word reading. This leads us to question current conceptualizations of DD and highlights how malleable definitions and research findings may be to the selection of measurement tools.

\section{CONCLUSIONS}

Several conclusions can be drawn from the study's findings. First, the PPVT-III does not necessarily have significantly higher correlations with the reading measures than the CPM. Differences between these measures are largely governed by the types of reading measures under examination. The PPVT-III appears to have stronger relationship with tasks involving orthographic processing and higher order functions such as working memory and linguistic comprehension. Second, both the PPVT-III and the CPM have significantly higher correlations with measures of reading comprehension, than with lower level decoding and word recognition skills. Third, as both of these measures of intelligence are weakly correlated with pseudo-word reading, their use in discrepancy and regression models of DD may be questioned. It is important to highlight that the choice of reading and intelligence measures can dictate who is identified as having a reading disability. More careful thought and understanding is required for the choice of measurement tools employed to assess these constructs and how test selection impacts on the diagnostic models used for DD.

\section{REFERENCES}

[1] Lyon GR. Towards a definition of dyslexia. Ann Dyslexia 1995; 45: 3-27.

[2] Fletcher JM, Francis DJ, Rourke BP, Shaywitz SE, Shaywitz BA. The validity of discrepancy-based definitions of reading disabilities. J Learn Disabil 1992; 25(9):551-61.

[3] Siegel LS. An evaluation of the discrepancy definition of dyslexia. J Learn Disabil 1992; 25(10): 618-29.

[4] Siegel LS. IQ-discrepancy definitions and the diagnosis of LD: introduction to a special issue. J Learn Disabil 2003; 36(1): 2-3.

[5] Shaywitz BA, Fletcher JM, Holahan J, Shaywitz SE. Discrepancy compared to low achievement definitions of reading disability: Results from the Connecticut Longitudinal Study. J Learn Disabil 1992; 25: 639-48.

[6] Meyer M. The ability-achievement discrepancy: does it contribute to an understanding of learning disabilities. Educ Psychol Rev 2000; 12(3): 315-37.

[7] Stanovich KE. Discrepancy definitions of reading disability: Has intelligence led us astray? Read Res Q 1991; 26: 7-29.

[8] Stage SA, Abbott RD, Jenkins JR, Berninger VM. Predicting response to early reading intervention from verbal IQ, reading related language abilities, attention ratings, and verbal IQ-word reading discrepancy: Failure to validate discrepancy method. J Learn Disabil 2003; 36(1): 24-33.

[9] Torgesen JK. Why IQ is relevant to the definition of learning disabilities. J Learn Disabil 1989; 22: 484-6.

[10] Siegel LS. Definitional and theoretical issues and research on learning disabilities. J Learn Disabil 1988; 21: 264-6.

[11] Siegel LS. Dyslexics vs poor readers: is there a difference? J Learn Disabil 1992; 25: 618-29.

[12] Siegel LS, Himel N. Socioeconomic status, age and the classification of dyslexics and poor readers: the dangers of using IQ scores in the definition of reading disability. Dyslexia 1998; 4: 90104.

[13] Siegel LS. Why we do not need intelligence tests scores in the definition and analyses of learning disabilities? J Learn Disabil 1989; 22: 514-8.

[14] Stanovich KE. Toward a more inclusive definition of dyslexia. Dyslexia 1996; 2: 154-66.

[15] Aaron PG. The paradoxical relationship between intelligence and reading disability. Percept Mot Skills1985; 61: 1251-61.

[16] Algozzine B, Ysseldyke JE, Shinn M. Identifying children with learning disabilities: When is a discrepancy severe? J Sch Psychol 1982; 20(4): 299-305. 
[17] Cone TE, Wilson LR. Quantifying a severe discrepancy: a critical analysis. Learn Disabil Q 1981; 4: 359-71.

[18] Flowers L, Meyer M, Lovato J, Wood F, Felton R. Does third grade discrepancy status predict the course of reading development? Ann Dyslexia. 2000; 50: 49-71.

[19] Vellutino FR, Scanlon DM, Lyon GR. Differentiating between difficult-to-remediate and readily remediated poor readers. More evidence against the IQ-achievement discrepancy definition of reading disability. J Learn Disabil 2000; 33(3): 223-38.

[20] Schulte A, Borich GD. Considerations in the use of difference scores to identify learning-disabled children. J Sch Psychol 1984; 22: $381-90$

[21] Wilson LR, Cone $T$. The regression equation method of determining academic discrepancy. J Sch Psychol 1984; 22: 95110 .

[22] Toth G, Siegel LS. A critical evaluation of the IQ-achievement discrepancy based definition of dyslexia. In: van den Bos KP, Ed. Current directions in dyslexia research. Lisse: Swets and Zeitlinger 1994; pp. 45-70.

[23] Gustafson S, Samuelsson S. Intelligence and dyslexia: Implications for diagnosis and intervention. Scand J Sch Psychol 1999; 40: 12734.

[24] Scarborough HS, Parker JD. Matthew effects in children with learning disabilities: Development of reading, IQ, and psychosocial problems from grade 2 to grade 8. Ann Dyslexia 2003; 53: 47-71.

[25] Stanovich KE. Explaining the variance in reading ability in terms of psychological processes: What have we learned? Ann Dyslexia 1986; 35: 67-96.

[26] Tønnessen FE. On defining dyslexia. Scand J Educ Res 1995; 39(2): 139-56.

[27] Cotton SM, Crewther DP, Crewther SG. Measurement error: implications for the discrepancy definitions of developmental dyslexia. Dyslexia 2005; 11: 186-202.

[28] Caruso JC, Witkiewitz K. Increasing the reliability of abilityachievement difference scores: an example using the Kaufman assessment battery for children. J Educ Meas 2002; 39(1): 39-58.

[29] Nunnally JC, Bernstein IH. Psychometric Theory. New York: McGraw-Hill, Inc 1994

[30] Zimmerman DW. A note on interpretation of formulas for the reliability of differences. J Educ Meas 1994; 31(2):143-7.

[31] Fletcher JM, Espy KA, Francis DJ, Davidson KC, Rourke BP, Shaywitz SE. Comparisons of cut-off and regression-based definitions of reading disabilities. J Learn Disabil 1989; 22: 33455.

[32] Anastasi A, Urbina S. Psychological testing. New Jersey: Prentice Hall 1997.

[33] Payne RW, Jones G. Statistics for the investigation of individual cases. J Clin Psychol 1957; 13: 115-21.

[34] Bishop DVM, Butterworth GE. Verbal-performance discrepancies: relationship to birth risk and specific reading retardation. Cortex 1980; 16: 375-89.

[35] Carver RP. Intelligence and reading ability in grades 2-12. Intelligence 1990; 1: 449-55.

[36] Naglieri JA. An examination of the relationship between intelligence and reading using the MAT-SF and MAST. J Psychoeducational Assess 1996; 14: 65-9.

[37] Naglieri JA, Ronning ME. The relationship between general ability using the Naglieri Nonverbal Ability Test (NNAT) and Stanford Achievement Test (SAT) Reading Achievement. J Psychoeduc Assess 2000; 18: 230-9.

[38] Naglieri JA. Do ability and reading achievement correlate? J Learn Disabil 2001; 34(4): 304-5.

[39] Vellutino FR. Further analysis of the relationship between reading achievement and intelligence. Response to Naglieri. J Learn Disabil 2001; 34(4): 306-10.

[40] Stanovich KE, Cunningham E, Freeman DJ. Intelligence, cognitive skills and reading progress. Read Res Q 1984; 19: 3.

[41] Jensen A. Straight talk about mental tests. New York: Free Press 1981.

[42] Stanovich KE. The right and wrong places to look for the cognitive locus of reading disability. Ann Dyslexia 1988; 38: 154-77.

[43] Stanovich KE. Matthew effects in reading: some consequences of individual differences in the acquisition of literacy. Read Res Q 1986; XXI: 360-405.

[44] Pollock J. IQ Tests. Dyslexia 2001; 7: 171-3.
[45] Ehri LC. Word reading by sight and by analogy in beginning readers. In: Hulme $\mathrm{C}$, Joshi RM, Eds. Reading and spelling: development and disorders. New Jersey: Lawrence Erlbaum Associates 1998; pp. 87-111.

[46] Spear-Swerling L, Sternberg RJ. The road not taken: an integrative theoretical model of reading disability. J Learn Disabil 1994; 27(2): 91-103.

[47] Hagtvet BE. Phonological and linguistic-cognitive precursors of reading abilities. Dyslexia 1997; 3: 163-77.

[48] Evans LD. A comparison of the impact of regression and simple difference discrepancy models on identification rates. J Sch Psychol 1992; 30: 17-29.

[49] Dunn LM, Dunn LM. Examiner's manual for the PPVT-III: peabody picture vocabulary test. $3^{\text {rd }}$ Ed. Minnesota: American Guidance Service 1997.

[50] Raven J, Raven JC, Court JH. Section 2: Coloured progressive matrices. Introducing the parallel version of the test. manual for the raven's progressive matrices and vocabulary scales. Great Britain: Oxford Psychologist Press 1998.

[51] Hoover WA, Gough PB. The simple view of reading. Reading and Writing 1990; 2: 127-60.

[52] Spooner AL, Baddeley AD, Gathercole SE. Can reading accuracy and comprehension be separated in the neale analysis of reading ability? Br J Educ Psychol 2004; 74: 187-204

[53] McMorris BJ, Clements J, Evans-Whipp T, et al. A comparison of methods to obtain active parental consent for an international study survey. Eval Rev 2004; 28(1): 64-83.

[54] Bornstein M, Rothstein H, Cohen J, Schoenfeld D. Sample Power. release $2^{\text {nd }}$ ed. USA: SPSS 2000 .

[55] Neisser U, Boodoo G, Bouchard TJ, et al. Intelligence: knowns and unknowns. Am Psychol 1996; 51(2): 77-101.

[56] Cotton SM, Kiely PM, Crewther DP, et al. A normative and reliability study for the raven's coloured progressive matrices for primary school-aged children from Victoria Australia. Pers Individ Dif 2005; 39: 647-59.

[57] Hodapp AF, Gerken KC. Correlations between scores for peabody picture vocabulary test III and the wechsler intelligence scale for children-III. Psychol Rep 1999; 84(3): 1139-42.

[58] Hodapp AF. Correlations between wechsler intelligence scale for children-III and peabody picture vocabulary test-revised. Psychol Rep 1997; 80(2): 491-6.

[59] Martin AW, Wiechers JE. Raven's colored progressive matrices and the wechsler intelligence scale for children. J Consult Psychol 1954; 18(2): 143-4.

[60] Neale MD. Neale analysis of reading ability revised - manual. Hawthorn, Victoria: Australian Council for Education Research 1991.

[61] Woodcock RW, Johnson MB. WJ-R tests of achievement: examiner's manual. In: Woodcock RW, Johnson B, Eds. woodcockjohnson psycho-educational battery - revised. Chicago: Riverside 1990.

[62] Sattler JM. Assessment of children. San Diego: Jerome M Sattler, Publisher, Inc 1992.

[63] Snowling MJ. Dyslexia. Oxford: Blackwell Publishers 2000.

[64] Nation K, Snowling MJ. Assessing reading difficulties: the validity and utility of current measures of reading skill. Br J Educ Psychol 1997; 67: 359-70.

[65] Tabachnick BG, Fidell LS. Using multivariate statistics. New York: Harper Collins Publishers, Inc 1996.

[66] Cohen J. Statistical power analysis for the behavioral sciences. 2nd ed. Hillsdale, NJ: Lawrence Erlbaum Associates, Inc 1988.

[67] May K, Hittner JB. Tests for comparing dependent correlations revisited: a monte carlo study. The J Exp Educ 1997; 65(3): 257 69.

[68] Groth-Marnat G. Handbook of psychological assessment with WAIS-III supplement. New York: John Wiley and Sons, Inc 1999.

[69] Joshi RM, Aaron PG. The component model of reading: simple view of reading made a little more complex. Read Psychol 2000; 21: 85-97.

[70] Ramus F. Outstanding questions about phonological processing in dyslexia. Dyslexia 2001; 7: 197-216.

[71] Goswami U. Why theories about developmental dyslexia require developmental designs. Trends Cogn Sci 2003; 7(12): 534-40.

[72] Stanovich KE. A model for studies of reading disability. Dev Rev 1993; 13: 225-45. 
[73] Lundberg I. The child's route into reading and what can go wrong. Dyslexia 2002; 8: 1-13.

[74] Rack JP, Snowling MJ, Olson RK. The nonword reading deficit in developmental dyslexia: a review. Read Res Q 1992; 27: 29-53.
[75] Shaywitz SE, Escobar MD, Shaywitz BA, Fletcher JM, Maruch R. Evidence that dyslexia may represent the lower tail of a normal distribution of reading ability. N Engl J Med 1992; 326(3): 145-50.

[76] Ramus F. Dyslexia: talk of two theories. Nature 2001; 412: 393 95.

(C) Cotton and Crewther; Licensee Bentham Open.

This is an open access article licensed under the terms of the Creative Commons Attribution Non-Commercial License (http://creativecommons.org/licenses/by$\mathrm{nc} / 3.0 /$ ) which permits unrestricted, non-commercial use, distribution and reproduction in any medium, provided the work is properly cited. 